\title{
High genetic contribution to anterior cruciate ligament rupture: Heritability 69\%
}

\author{
Karin Magnusson 지 , ${ }^{1,2}$ Aleksandra Turkiewicz, ${ }^{1}$ Velocity Hughes, ${ }^{1}$ Richard Frobell, ${ }^{3}$ \\ Martin Englund ${ }^{1}$
}

- Additional material is published online only. To view please visit the journal online (http://dx.doi.org/10.1136/ bjsports-2020-102392).

'Lund University, Faculty of Medicine, Department of Clinical Sciences Lund, Orthopaedics, Clinical Epidemiology Unit, Lund, Sweden

2Diakonhjemmet Hospital, Department of Rheumatology, National Advisory Unit on Rehabilitation in Rheumatology, Oslo, Norway

${ }^{3}$ Lund University, Faculty of Medicine, Department of Clinical Sciences Lund, Orthopaedics, Lund, Sweden

\section{Correspondence to}

Karin Magnusson, Clinical Epidemiology Unit, Orthopaedics Department of Clinical Sciences Lund, Lund University, 22185 Lund, Sweden;

karin.magnusson@med.lu.se

Accepted 24 August 2020

Published Online First

7 December 2020
ABSTRACT

Objectives We aimed to determine the lifetime genetic risk for anterior cruciate ligament $(\mathrm{ACL})$ rupture.

Methods We used a twin study approach, linking the Swedish Twin Register with national healthcare data to form a 30 year, population wide, longitudinal twin cohort. We studied ACL rupture in this cohort of 88414 identical and fraternal twins, aged $\geq 17$ years, to determine the familial risk and heritability of ACL rupture.

Results The incidence rate of ACL rupture was 70 (95\% $\mathrm{Cl} 66$ to 74) per 100000 person years. The familial risk, which is the excess risk ratio (RR) of the second twin having $A C L$ rupture given that the first twin has had such a rupture, was higher in identical twin pairs $(R R=8.6$, $95 \% \mathrm{Cl} 6.2$ to 11.0$)$ than in fraternal twin pairs ( $R R=1.9$, $95 \% \mathrm{Cl} 0.9$ to 3.0). The overall heritability of $\mathrm{ACL}$ rupture was high, 69\% (95\% Cl 47 to 91), increasing from $60 \%$ at age 17 years to $80 \%$ at age 60 years. Women and men had similar familial risk and heritability of $\mathrm{ACL}$ rupture.

Conclusion The genetic contribution to $\mathrm{ACL}$ rupture of $\sim 69 \%$ is high and suggests strong familial clustering. If clinicians recognise the high genetic risk of such injury, they may be better able to counsel athletes whose near relatives have had $A C L$ rupture.

\section{BACKGROUND}

Anterior cruciate ligament (ACL) rupture is common in contact sports and in military service personnel. ${ }^{1-3}$ The injury often leads to reduced health related quality of life and is associated with up to 10 -fold increased risk for osteoarthritis of the knee. ${ }^{45}$ Well known risk factors for ACL rupture in contact sports are playing surfaces with high friction, type of footwear, speed and pivoting, among others. ${ }^{6}$ However, ACL rupture is also associated with risk factors that are largely genetically mediated, including bone geometry of the knee, malalignment and generalised joint laxity. ${ }^{6-8}$ One study revealed a threefold increased risk for ACL injury associated with joint hypermobility. ${ }^{7}$ Hypermobility has a reported genetic contribution of $57-89 \%$ based on a study of female twins. ${ }^{9}$ Despite the high genetic contribution to several potential risk factors for ACL rupture, two systematic reviews and smaller case control studies have been inconclusive as to what extent the injury is influenced by genetic factors. ${ }^{10-13}$

Twin studies are exceptionally well suited to explore the genetic contribution to a trait, by allowing for individual estimation of the genetic versus environmental sources of variance in that trait. ${ }^{14}$ Specifically, to estimate the genetic source of variation, differences in similarities between identical and fraternal twins are utilised (who we know share $100 \%$ vs $50 \%$ of their genes, respectively), providing information that can be used in further studies of risk prediction models.

To our knowledge, the genetic contribution to ACL rupture has never been quantified using the twin study approach. We aimed to use the world's largest twin register ${ }^{15}$ to explore the genetic contribution to ACL rupture in both men and women across the lifespan.

\section{METHODS}

Data sources

We studied the incidence of cruciate ligament injury in Swedish twins using a population based longitudinal cohort design. The final sample included 88414 twins from the Swedish Twin Registry born 1911-1999, whose zygosity was determined based on DNA testing (13\%) or questions about intra-pair physical similarities in childhood (figure 1). ${ }^{15}$ Data from the Swedish Twin Registry were linked on an individual level to the Swedish National Patient Register (NPR) in 2016. The NPR contains diagnostic codes of diseases and injuries obtained in specialist care from 1987 and onwards, including data on every hospitalisation (from 1987 to 2016), 1 day surgery (from 1997 to 2016) and specialist outpatient healthcare (from 2001 to 2016). These data were further linked with individual level data on death and level of education, obtained from the National Board of Health and Welfare and the longitudinal integration database for health insurance and labour market studies (LISA) from Statistics Sweden. The study was approved by the ethical review board at Lund University, Sweden.

\section{Study design}

We included twins aged 17 years or older, with a minimum follow-up time of 1 year in the NPR. Both twins in the pair were required to be alive for at least the first year of follow-up. Follow-up began on the date the twins turned 17 years or, for twins who turned 17 years before coverage began in the NPR, from 1987 when they were aged 18 or more.

\section{Patient and public involvement}

No patients or public were involved in this study.

\section{Outcome: cruciate ligament injury}

Incident cruciate ligament injuries with date of diagnosis are recorded in the NPR according to the International Classification of Diseases and Related Health Problems (ICD-9 and ICD-10) from 1987 


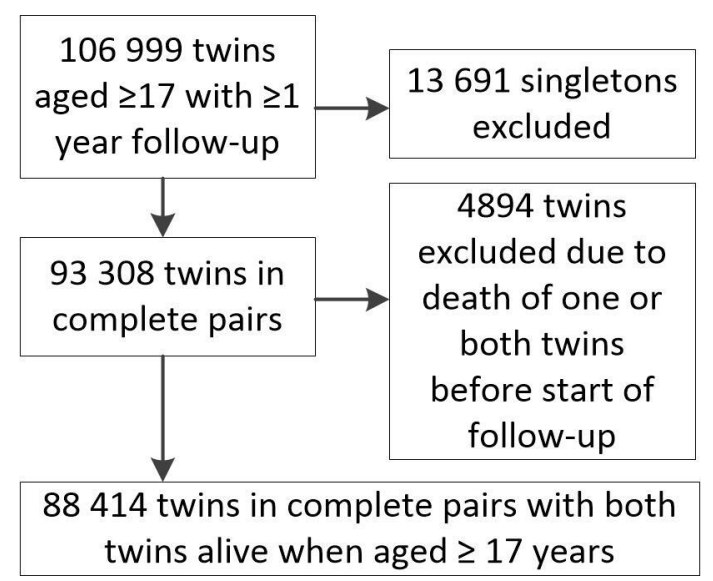

Figure 1 Flowchart of included and excluded persons.

until 2016. We included the Swedish versions of ICD-10 codes S83.5, S83.5R, S83.5S, S83.5X, and S83.7, and the ICD-9 code $844 \mathrm{C}$ for acute cruciate ligament injury (online supplemental figure S1). The diagnostic codes were determined by evaluating physicians using clinical examinations, arthroscopic visualisation, MRI or any combination of these, and could include both reconstructed ruptures and non-reconstructed ruptures, that were hospitalised and non-hospitalised. For each twin, the endpoint of follow-up was the date of first diagnosis of the injury, or when he or she died, whichever came first. We will refer to the index cases as cases having ACL rupture. Twins who did not have an ACL rupture, or did not die prior to study end, were censored at 31 December 2016.

\section{Statistical analyses}

The genetic contribution to a trait can be estimated using the classical twin model, the 'ACE/ADE' model. In this model, differences in genetic intra-pair dependencies within identical and non-identical twin pairs are utilised to estimate variance components that are due to genetic versus environmental factors. 'A' represents additive genetic factors, ' $\mathrm{C}$ ' represents shared environmental factors, 'D' represents dominant genetic factors and ' $E$ ' represents environmental factors unique to each twin in a pair. ${ }^{16}$ The heritability represents the percentage of the total variance in a trait that is due to additive (A) and/or dominant (D) genetic factors.

In estimating heritability, we applied a joint threshold liability model for the twin pairs and studied the rate at which pairs became concordant (similar) for ACL rupture over time. The threshold liability model is suitable when censoring is administrative- that is, similar for both twins in a pair, as was the case in this register study. ${ }^{1617}$ Thus we classified ACL ruptures and death as different types of failures to ensure the same censoring (at study end) for both twins, and accounted for the censoring using inverse probability weighting, as previously recommended. ${ }^{16} 17$ With this approach, twin pairs were considered at risk for ACL rupture as long as both twins were alive and uncensored. We initially compared ACE, ADE and AE models by tetrachoric intra-pair correlations (ie, intra-pair correlations for binary traits) and Akaike Information Criteria (AIC) to find the best fitting model, in order to subsequently quantify the contributions of each of A, C, D and E.

Further, we applied a flexible model without assumptions of the underlying ACDE structure or probability weighting, to estimate casewise concordance (the conditional probability that a twin gets ACL rupture given that the co-twin has had a rupture) and the relative recurrence risk ratio. The latter is the excess risk of ACL rupture for a twin given that the co-twin has had the injury, relative to the marginal (population) risk (ie, the overall risk for the injury in the study sample, treating it as a population of unrelated individuals), calculated over the follow-up period of $0-30$ years using the bptwin function. ${ }^{16}$ The relative recurrence risk ratio can thus be interpreted as an excess familial risk, which is determined by degree of shared genetics of twins in a pair. The magnitude of familial risk and its difference between monozygotic (MZ) and dizygotic (DZ) twins provides information of the relevance of familial factors in the aetiology of the trait of interest.

Additionally, to infer whether the genetic contribution to ACL rupture interacts with the age at which the diagnosis was received, we graphed heritabilities and familial risk for the injury over the lifespan for MZ and DZ twins from age 17 years. In accordance with available methods, age specific familial risk was calculated assuming that everyone was observed from age $0-$ that is, ages $0-105$ years in our study sample using the twinlm. time function. ${ }^{16}$

Finally, we also explored potential sex differences in familial risk, and tetrachoric correlations for ACL rupture in male and female MZ twins, same sex DZ twins and opposite sex DZ twins. All analyses were performed using the METS package in $\mathrm{R}$ (the R Project for Statistical Computing), V3.4.1.

\section{RESULTS}

Of the 88414 twins aged $\geq 17$ years and having $\geq 1$ year of follow-up (figure 1), 1395 (1.6\%) were diagnosed with ACL rupture and 17501 (19.8\%) died during the follow-up of up to 30 years. The sample consisted of $33 \%$ identical and $67 \%$ fraternal twins. Thirty-five per cent could be observed from the age of $17,90 \%$ of the injuries occurred before age 60 years and $90 \%$ of deaths occurred after age 60 years, implying limited competing risk of death. Individuals with ACL rupture were generally younger and had a higher education at the start of follow-up than individuals without such a rupture (table 1 ). The average incidence rate of ACL rupture per 1000 person years for men and women was 0.70 (95\% CI 0.66 to 0.74 ) (table 2). The majority of cases had injury to multiple structures of the knee that included the ACL (online supplemental figure S1). The age of peak occurrence was 18 years $(117 / 1395,8.4 \%)$ whereas the median (IQR) age of occurrence was 32 (21-50) years.

\section{Heritability}

The overall heritability of ACL rupture was 0.69 (95\% CI 0.47 to 0.91), as estimated from an ADE model adjusted for censoring. The ADE model showed the best model fit based on AIC values and according to correlation patterns (MZ:DZ twin ratio of $3: 1$, indicating mainly dominant genetics) (online supplemental table S1, table 3). However, similar heritability estimates were found for ACE and AE models (online supplemental table S1). From the start of follow-up at age 17 years, heritabilities were relatively constant across the lifespan, although increasing slightly towards age 60 (figure 2A). The familial risk for ACL rupture was higher for MZ than DZ twins, especially from age 35 onwards (figure 2B). Also, the familial risk for DZ twins was higher than 1 (a risk ratio of 1 implies the same risk in DZ twins as marginal risk) from age 30 to 35 years onwards (figure $2 \mathrm{~B}$ ).

\section{Age and sex differences in familial dependency}

The familial risks were higher among MZ twins than same sex DZ twins, for both men and women (table 3). The MZ familial 
Table 1 Participants' characteristics at the start of follow-up and number of pairs affected by anterior cruciate ligament rupture during follow-up

\begin{tabular}{|c|c|c|c|c|c|}
\hline & \multirow[b]{2}{*}{ All } & \multicolumn{2}{|l|}{ Men } & \multicolumn{2}{|l|}{ Women } \\
\hline & & No $A C L$ rupture & $\mathrm{ACL}$ rupture & No $A C L$ rupture & $\mathrm{ACL}$ rupture \\
\hline Twin, individual level $(n)^{*}$ & 88414 & 40553 & 673 & 46466 & 722 \\
\hline Age at start of follow-up (years) (median (IQR)) & $32(17-47)$ & $32(17-46)$ & $17(17-31)$ & $33(17-48)$ & $17(17-31)$ \\
\hline $\begin{array}{l}\text { Primary schoolt } \\
(\leq 9 \text { years) }(\mathrm{n}(\%))\end{array}$ & $26612(30.1)$ & $12652(31.2)$ & $117(17.4)$ & $13756(29.6)$ & $87(12.1)$ \\
\hline $\begin{array}{l}\text { Upper secondary schoolt } \\
\text { (1-4 years) (n (\%)) }\end{array}$ & $36335(41.1)$ & $17188(42.4)$ & $325(48.3)$ & $18520(39.9)$ & $302(41.8)$ \\
\hline $\begin{array}{l}\text { College/university }{ }^{\circ} \\
\text { (>1 years) (n (\%)) }\end{array}$ & $25467(28.8)$ & $10713(26.4)$ & $231(34.3)$ & $14190(30.5)$ & $333(46.1)$ \\
\hline Body mass index $\left(\mathrm{kg} / \mathrm{m}^{2}\right)$ (mean (SD)) & $23.3(3.5)$ & $23.9(3.3)$ & $24.2(3.4)$ & $22.7(3.7)$ & $22.9(3.41)$ \\
\hline Twin, pair level $(\mathrm{N}) \ddagger$ & 44207 & & & & \\
\hline Monozygotic pairs (N) & 14531 & 6204 & 214 & 7863 & 250 \\
\hline Dizygotic pairs, same sex (N) & 17409 & 7830 & 232 & 9099 & 248 \\
\hline Dizygotic pairs, opposite sex§ (N) & 12267 & 11866 & 401 & 11866 & 401 \\
\hline
\end{tabular}

*Lower case ' $n$ ' represents individuals.

tHighest level of education reached at the start of follow-up.

fUpper case ' $\mathrm{N}$ ' represents pairs. Pair level $\mathrm{N}$ for anterior cruciate ligament rupture includes pairs in which at least one twin in the pair was affected.

$\S$ Pairs consisting of male and female twins- that is, the same $\mathrm{N}$ values are presented for men and women.

$\mathrm{ACL}$, anterior cruciate ligament.

risks, casewise concordances and intra-pair correlations were similar for both sexes, indicating no quantitative sex differences. Opposite sex DZ twins had a higher marginal risk than same sex DZ twins, yet the familial dependency measures were similar to those for same sex DZ twins, also indicating no qualitative sex differences. However, results for DZ twins should be interpreted with care due to the low number of observed concordant pairs. For this reason, we did not attempt to estimate or graph sex specific heritability.

\section{DISCUSSION}

In this study of the genetic contribution to doctor diagnosed ACL rupture, with up to 30 years of follow-up of more than 88 000 Swedish twins, we found a remarkably high overall genetic contribution of nearly $70 \%$. In comparison, the overall heritability of cancer is reported to be around $33 \%$ and the heritability of eye colour is $98 \% .^{1418}$

\section{Comparison with previous studies}

We are aware of no other twin study of knee injury for an effective comparison of our findings, and the heritability of ACL rupture seems to never have been previously studied. However, we confirm and nuance previous suggestions of family associations between individuals surgically treated for ACL rupture, although we could not confirm previously reported sex differences in the genetic contribution to ACL rupture. In a case control study of patients undergoing ACL reconstruction, it was reported that men with ACL ruptures were more likely to have a relative with an ACL injury compared with men without ACL ruptures, while no such associations could be found for women. ${ }^{12}$ Also, a more recent study reported that having a parent who suffered an ACL rupture, in combination with higher anterior-posterior knee laxity and body mass index, was predictive of ACL rupture but for women only. ${ }^{19}$ In our much larger, longitudinal and population based cohort study, the familial risks were similar for male and female twin pairs in both $\mathrm{MZ}$ and $\mathrm{DZ}$ twins, indicating that genetics and common environmental factors impact injury risk in a similar way in men and women. This observation was strengthened by our analyses of opposite sex DZ twins compared with male and female same sex DZ twins, suggesting no sex differences in familial risks.

\section{Clinical implications}

Our findings have several important implications. First, familial risk is currently not included in cruciate ligament rupture risk prediction and reduction; we feel this important determinant is often neglected in studies of injury prevention and treatment programmes. ${ }^{20}{ }^{21}$ Here we report a large excess familial risk for ACL rupture in both $\mathrm{MZ}$ and $\mathrm{DZ}$ twin pairs compared with the reference risk in the population. Because DZ twin pairs are genetically similar to siblings, sharing on average $50 \%$ of their genes, our results imply that preventive strategies for knee injury may be of particular importance for an individual if his/ her sibling (or parent, who also shares $50 \%$ of genes with their children) has already experienced a cruciate ligament rupture. Specifically, our findings imply that the risk for having ACL

Table 2 Incidence rates of anterior cruciate ligament rupture per 1000 person years across ages for men and women in the Swedish Twin Register

\begin{tabular}{|c|c|c|c|c|c|c|}
\hline & \multicolumn{3}{|l|}{ Men } & \multicolumn{3}{|l|}{ Women } \\
\hline & Person years & $\mathrm{N}^{*}$ & Rate $(95 \% \mathrm{Cl})$ & Person years & $N^{*}$ & Rate $(95 \% \mathrm{Cl})$ \\
\hline $18-20$ years & 60197 & 139 & 2.31 (1.96 to 2.73 ) & 65860 & 179 & 2.71 (2.35 to 3.15$)$ \\
\hline $40-60$ years & 340300 & 168 & 0.49 (0.42 to 0.57$)$ & 379600 & 203 & 0.53 (0.47 to 0.61$)$ \\
\hline$>60$ years & 271300 & 74 & 0.27 (0.22 to 0.34$)$ & 353000 & 80 & 0.23 (0.18 to 0.28$)$ \\
\hline
\end{tabular}

\footnotetext{
*Number of incident cases of anterior cruciate ligament rupture.
} 
Table 3 Estimates of familial risk for anterior cruciate ligament rupture in monozygotic and dizygotic men and women.

\begin{tabular}{|c|c|c|c|c|c|}
\hline & \multicolumn{2}{|l|}{ Men } & \multicolumn{2}{|l|}{ Women } & \multirow{2}{*}{$\begin{array}{l}\text { Opposite sex } \\
\text { DZ (n=12 267) }\end{array}$} \\
\hline & $D Z(n=8062)$ & $M Z(n=6418)$ & DZ ( $n=9347)$ & $M Z(n=8113)$ & \\
\hline Pairs concordant for $\mathrm{ACL}$ rupture $(\mathrm{n}(\%))$ & $2(0.9)$ & $18(8.4)$ & $4(1.6)$ & $19(7.6)$ & $7(1.7)$ \\
\hline $\begin{array}{l}\text { Marginal risk (ie, population risk)* } \\
(95 \% \mathrm{Cl})\end{array}$ & 0.02 (0.01 to 0.02 ) & 0.02 (0.01 to 0.02 ) & 0.01 (0.01 to 0.02 ) & 0.02 (0.01 to 0.02 ) & 0.04 (0.04 to 0.06$)$ \\
\hline $\begin{array}{l}\text { Casewise concordancet } \\
(95 \% \mathrm{Cl})\end{array}$ & 0.02 (0.00 to 0.07$)$ & 0.14 (0.09 to 0.21$)$ & 0.04 (0.01 to 0.09$)$ & $0.13(0.09$ to 0.20$)$ & $0.07(0.04$ to 0.13$)$ \\
\hline $\begin{array}{l}\text { Familial risk (ie, relative recurrence risk ratio) } \neq \\
(95 \% \mathrm{Cl})\end{array}$ & 1.19 (0.00 to 2.81$)$ & 8.89 (5.28 to 12.44$)$ & 2.38 (0.14 to 4.62$)$ & $8.71(5.25$ to 12.17$)$ & $1.42(0.68$ to 2.17$)$ \\
\hline $\begin{array}{l}\text { Tetrachoric correlation, r£ } \\
(95 \% \mathrm{Cl})\end{array}$ & $0.03(-0.20$ to 0.25$)$ & 0.48 (0.35 to 0.58$)$ & $0.15(-0.04$ to 0.33$)$ & $0.46(0.34$ to 0.56$)$ & $0.09(-0.06$ to 0.23$)$ \\
\hline
\end{tabular}

${ }^{*}$ The marginal risk is the population risk — that is, the risk of being diagnosed with ACL rupture without taking familial dependency into account.

tCasewise concordance is the risk of a twin being diagnosed with ACL rupture given that the co-twin has already been diagnosed with the injury.

‡The familial risk is the excess risk of ACL rupture for a twin given that the co-twin has had the injury.

$\S$ The tetrachoric correlation is the intra-pair correlation between two theorised normally distributed continuous latent variables, from two observed binary variables (ACL rupture in twin 1 and $\mathrm{ACL}$ rupture in twin 2) and is used for calculating the heritability.

$\mathrm{ACL}$, anterior cruciate ligament; $\mathrm{DZ}$, dizygotic; $\mathrm{MZ}$, monozygotic.

rupture would increase by $\sim 20 \%$ to $\sim 140 \%$ if a sibling has ACL rupture (table 2). These results suggest that future studies of risk prediction should consider all risk factors, including injury in family members, and explore potential interactions between these factors and other risk factors, such as anatomy, sport skill level, neuromuscular control, body composition, etc, in order to enable even more targeted prevention and treatment approaches for both knee injury and secondary post-traumatic knee osteoarthritis. $^{2122}$

Our findings may also have further implications for the aetiology of cruciate ligament rupture. Most importantly, the potential age differences observed in heritability raise novel hypotheses regarding the 'natural' life course of the ligament tissue itself. More specifically, the increasing heritability and difference in familial risk between MZ and DZ twins from age 35 years and onwards may imply a genetically determined early degeneration of joint tissues. ${ }^{23} 24$ These degenerative processes may further increase the risk of osteoarthritis, which in several studies has been reported to be largely genetically driven, particularly at older ages. ${ }^{24-26}$

However, the age dependence in observed heritability may also be due to the set-up of our study (including both young and older individuals), and future studies on the genetic overlap between knee injury and osteoarthritis may provide important details on the transition phase between the two. Also, specific anatomical variations of knee bone shapes, such as tibial slope and inter-chondylar notch width, have been reported to increase the risk of ACL injury. ${ }^{27}$ These anatomical variations are likely largely genetically determined, strengthening the hypothesis that such anatomical risk factors may serve as proxies for the genetic contribution.

We note that our heritability measures apply to the entire population, not individuals. The heritability should be interpreted as the degree of variation in a phenotypic trait that is due to genetic variation between individuals in that population. In this regard, it is possible that genetics may have a larger contribution to ACL
A

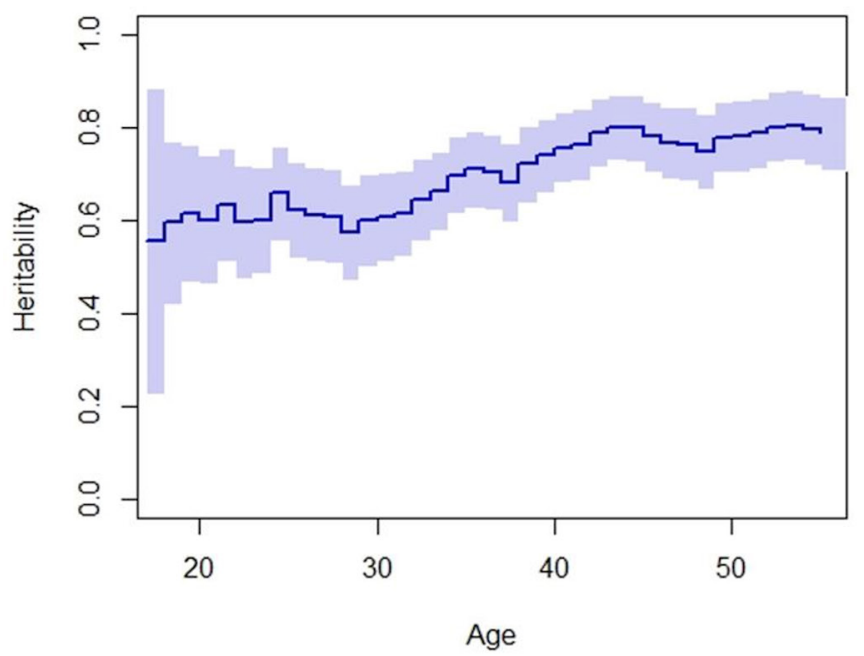

B

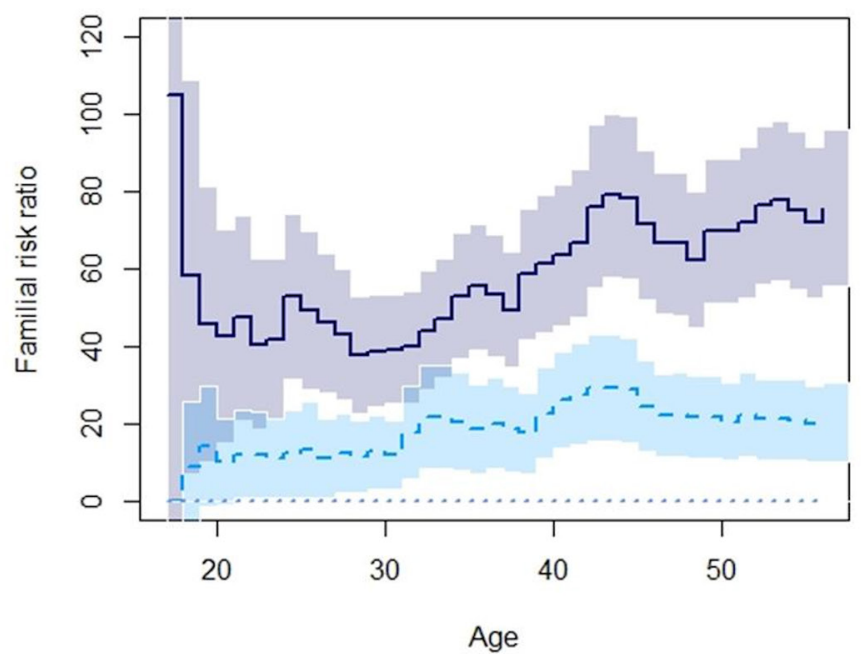

Figure 2 Heritability and familial risk of anterior cruciate ligament (ACL) rupture by age at diagnosis. (A) Heritability of ACL rupture by age at diagnosis, with $95 \% \mathrm{Cl}$. (B) Familial risk (the relative recurrence risk ratio) of $\mathrm{ACL}$ rupture by age at diagnosis, for monozygotic (solid line) and dizygotic twins (dashed line, includes both same sex and opposite sex pairs), with 95\% confidence intervals. The dotted line represents the reference population risk, assuming genetically unrelated individuals (risk ratio=1.00). 
tears in some individuals, whereas environmental factors may be the larger contributor to tears in other individuals.

\section{Strengths and limitations}

An important strength of this study was the use of the world's largest twin register with virtually no selection bias, allowing for a unique 30 year prospective population based twin study of age and sex differences in the genetics of ACL rupture, using individual level data. Our study of incident ACL rupture covering the entire twin population of Sweden is likely to be representative for industrialised countries with a healthcare system, giving equal access to all inhabitants. We found our incidence of ACL rupture to be comparable with previous reports of population incidence in Sweden and other western countries. ${ }^{28} 29$

We note at least five limitations. First, the ICD-10 codes rarely differentiated between ACL and posterior cruciate ligament ruptures and we could not validate the diagnoses. Still, the vast majority were anticipated to be ACL ruptures due to their much higher incidence. ${ }^{30}$ Despite ACL rupture being among the most frequent knee injuries, ${ }^{1}$ we cannot exclude certain misclassifications in our study. However, we expect the risk of misclassification to be similar for both twins in a pair. Further, the validity of the diagnostic coding in the NPR has been reported to be high for a variety of conditions. ${ }^{29} 31$

A second limitation is that we may have underestimated the concordance of ACL rupture for twin pairs that were not covered by the NPR at young ages. Yet, any potential underestimation in this group will be similar for MZ and DZ twins, and thus will not impact our heritability estimates.

A third limitation is that we cannot conclude which mechanisms contributed to the high genetic risk. As an example, we cannot differentiate between contact versus non-contact injuries and complete versus partial tears. However, in such a large cohort, followed for such a long time, we consider everyone to be at the same risk of the different types of injuries, with limited impact on our findings.

Another important limitation is the possibility of violation of the assumptions of the classical twin model. This includes violation of the equal environment assumption, which would imply that the higher concordance among MZ twins may be due to environmental factors that are more shared in MZ than in DZ twin pairs (eg, differences in degrees of shared sports participation). Unfortunately, we lack data on environmental risk factors for ACL rupture to adjust our models.

We note the sparse data for concordance in DZ twins, which may have resulted in rather wide $95 \%$ CI for heritabilities and the potential inflation of familial risks (table 3). Also, there was a small difference in AIC $(\leq 2)$ between models (online supplemental table S1), making it challenging to differentiate and determine the nature of genetic contribution. However, this is often the case with classical twin models, and we suggest future studies could include other first degree relatives, study twin adoptees and/or use more sophisticated models in order to better identifying potential gene-gene- and gene-environment interactions. $^{3233}$

\section{CONCLUSIONS}

We found a high genetic contribution to ACL rupture that was similar for men and women. Our findings may have important implications for enabling individualised injury prevention programmes in the future, through the inclusion of data on cruciate ligament injury in near relatives when developing and validating risk prediction models.
What are the new findings?

- By analysing the world's largest twin register, we found that the genetic contribution to anterior cruciate ligament rupture is high, $69 \%$.

- Our findings imply that the risk for having an anterior cruciate ligament rupture increases by $\sim 20 \%$ to $~ 140 \%$, if a sibling has anterior cruciate ligament rupture.

\section{How might it impact on clinical practice in the future?}

- This new knowledge should influence individualised risk prediction for anterior cruciate ligament rupture.

Correction notice This article has been corrected since it published Online First. A typographical error in the abstract has been corrected.

Twitter Karin Magnusson @karinmgnssn

Acknowledgements We would like to acknowledge the Swedish Twin Registry, and in particular Barbro Sandin and Patrik Magnusson for access to data and data management. The Swedish Twin Registry is managed by the Karolinska Institute and receives funding through the Swedish Research Council under grant No 201700641.

Contributors KM had access to all of the data in the study and takes full responsibility for the integrity of the data and the accuracy of the data analysis. KM performed statistical analyses and drafted the manuscript. AT, VH, RF and ME contributed with acquisition of the data, conceptual design, analyses and interpretation of the results. All authors contributed in drafting the article or critically revising it for important intellectual content. All authors gave final approval for the version to be submitted.

Funding The study was funded by the Swedish Research Council (E0234801), the Greta and Johan Kock Foundation, the Swedish Rheumatism Association, the Österlund Foundation, Governmental Funding of Clinical Research within the National Health Service (ALF) and the Faculty of Medicine, Lund University, Sweden.

Competing interests None declared.

Patient consent for publication Not required.

Ethics approval The study was approved by the ethical review board at Lund University, Sweden.

Provenance and peer review Not commissioned; externally peer reviewed.

Data availability statement No data are available. The data are deidentified participant data not available for public use.

\section{ORCID iD}

Karin Magnusson http://orcid.org/0000-0003-4851-5794

\section{REFERENCES}

1 Spindler KP, Wright RW. Clinical practice. Anterior cruciate ligament tear. N Eng/ J Med 2008;359:2135-42.

2 Collins M, September AV, Posthumus M. Biological variation in musculoskeletal injuries: current knowledge, future research and practical implications. Br J Sports Med 2015;49:1497-503.

3 Swenson DM, Collins CL, Best TM, et al. Epidemiology of knee injuries among U.S high school athletes, 2005/2006-2010/2011. Med Sci Sports Exerc 2013;45:462-9.

4 Filbay SR, Culvenor AG, Ackerman IN, et al. Quality of life in anterior cruciate ligament-deficient individuals: a systematic review and meta-analysis. $\mathrm{Br}$ J Sports $\mathrm{Med}$ 2015;49:1033-41.

5 Whittaker JL, Toomey CM, Woodhouse LJ, et al. Association between MRI-defined osteoarthritis, pain, function and strength 3-10 years following knee joint injury in youth sport. Br J Sports Med 2018;52:934-9.

6 Smith HC, Vacek P, Johnson RJ, et al. Risk factors for anterior cruciate ligament injury: a review of the literature - part 1: neuromuscular and anatomic risk. Sports Health 2012;4:69-78

7 Uhorchak JM, Scoville CR, Williams GN, et al. Risk factors associated with noncontact injury of the anterior cruciate ligament: a prospective four-year evaluation of 859 West Point cadets. Am J Sports Med 2003;31:831-42.

8 Hertel J, Dorfman JH, Braham RA. Lower extremity malalignments and anterior cruciate ligament injury history. J Sports Sci Med 2004;3:220-5. 
9 Hakim AJ, Cherkas LF, Grahame R, et al. The genetic epidemiology of joint hypermobility: a population study of female twins. Arthritis Rheum 2004;50:2640-4.

10 Kaynak M, Nijman F, van Meurs J, et al. Genetic variants and anterior cruciate ligament rupture: a systematic review. Sports Med 2017:47:1637-50.

11 John R, Dhillon MS, Sharma S, et al. Is there a genetic predisposition to anterior cruciate ligament tear? A systematic review. Am I Sports Med 2016;44:3262-9.

12 Myer GD, Heidt RS, Waits C, et al. Sex comparison of familial predisposition to anterior cruciate ligament injury. Knee Surg Sports Traumatol Arthrosc 2014;22:387-91.

13 Flynn RK, Pedersen CL, Birmingham TB, et al. The familial predisposition toward tearing the anterior cruciate ligament: a case control study. Am I Sports Med 2005;33:23-8.

14 Mucci LA, Hjelmborg JB, Harris JR, et al. Familial risk and heritability of cancer among twins in Nordic countries. JAMA 2016;315:68-76.

15 Magnusson PKE, Almqvist C, Rahman I, et al. The Swedish Twin Registry: Establishment of a biobank and other recent developments. Twin Res Hum Genet 2013;16:317-29.

16 Scheike TH, Holst KK, Hielmborg JB. Estimating twin concordance for bivariate competing risks twin data. Stat Med 2014;33:1193-204.

17 Holst KK, Scheike TH, Hjelmborg JB. The liability threshold model for censored twin data. Comput Stat Data Anal 2016;93:324-35.

18 Bito LZ, Matheny A, Cruickshanks KJ, et al. Eye color changes past early childhood. The Louisville Twin Study. Arch Ophthalmol 1997;115:659-63.

19 Vacek PM, Slauterbeck JR, Tourville TW, et al. Multivariate analysis of the risk factors for first-time noncontact ACL injury in high school and college athletes: a prospective cohort study with a nested, matched case-control analysis. Am I Sports Med 2016:44:1492-501.

20 Kiani A, Hellquist E, Ahlqvist K, et al. Prevention of soccer-related knee injuries in teenaged girls. Arch Intern Med 2010;170:43-9.

21 Frobell RB, Roos EM, Roos HP, et al. A randomized trial of treatment for acute anterior cruciate ligament tears. N Engl J Med 2010;363:331-42.
22 Missitzi J, Geladas N, Klissouras V. Heritability in neuromuscular coordination: implications for motor control strategies. Med Sci Sports Exerc 2004;36:233-40.

23 Hasegawa A, Otsuki S, Pauli C, et al. Anterior cruciate ligament changes in the human knee joint in aging and osteoarthritis. Arthritis Rheum 2012;64:696-704.

24 Magnusson K, Turkiewicz A, Englund M, et al. Nature vs nurture in knee osteoarthritis - the importance of age, sex and body mass index. Osteoarthritis Cartilage 2019;27:586-92

25 Hochberg MC, Yerges-Armstrong L, Mitchell BD. Osteoarthritis susceptibility genes continue trickling in. Lancet 2012;380:785-7.

26 Zhai G, Hart DJ, Kato BS, et al. Genetic influence on the progression of radiographic knee osteoarthritis: a longitudinal twin study. Osteoarthritis Cartilage 2007;15:222-5.

27 Sturnick DR, Vacek PM, DeSarno MJ, et al. Combined anatomic factors predicting risk of anterior cruciate ligament injury for males and females. Am I Sports Med 2015;43:839-47

28 Sanders TL, Maradit Kremers H, Bryan AJ, et al. Incidence of anterior cruciate ligament tears and reconstruction: a 21-year population-based study. Am J Sports Med 2016:44:1502-7.

29 Nordenvall R, Bahmanyar S, Adami J, et al. A population-based nationwide study of cruciate ligament injury in Sweden, 2001-2009: incidence, treatment, and sex differences. Am J Sports Med 2012;40:1808-13.

30 Olsson O, Isacsson A, Englund M, et al. Epidemiology of intra- and peri-articular structural injuries in traumatic knee joint hemarthrosis - data from 1145 consecutive knees with subacute MRI. Osteoarthritis Cartilage 2016;24:1890-7.

31 Ludvigsson JF, Andersson E, Ekbom A, et al. External review and validation of the Swedish National Inpatient Register. BMC Public Health 2011;11:450.

32 Mayhew AJ, Meyre D. Assessing the heritability of complex traits in humans: methodological challenges and opportunities. Curr Genomics 2017;18:332-40.

33 Buil A, Brown AA, Lappalainen T, et al. Gene-Gene and gene-environment interactions detected by transcriptome sequence analysis in twins. Nat Genet 2015;47:88-91. 